\title{
Physician experiences of patient-centered and team- based ward rounding - an interview based case-study
}

\author{
Fredrik Baathe ${ }^{1,2,3}$, Gunnar Ahlborg J ${ }^{2,4}$, Annica Lagstrom ${ }^{1}$, Lars Edgren ${ }^{1}$, Kerstin Nilsson ${ }^{1}$ \\ 1. Institute of Health and Care Sciences, Sahlgrenska Academy at Gothenburg University, Gothenburg, Sweden. \\ 2. Institute of Stress Medicine, Region Västra Götaland, Gothenburg, Sweden. 3. Sahlgrenska University Hospital, \\ Gothenburg, Sweden. 4. Institute of Medicine, Sahlgrenska Academy at Gothenburg University, Gothenburg, Sweden.
}

Correspondence: Fredrik Baathe. Address: Registercentrum VGR, Medicinaregatan 18 G, 41345 Gothenburg, Sweden. E-mail: fredrik.baathe@vgregion.se

Received: J une 24, 2014

DOI : $10.5430 /$ jha.v3n6p127
Accepted: September 5, 2014

URL: http://dx.doi.org/10.5430/jha.v3n6p127

\section{Abstract}

Background: Rounding has long traditions within hospital-based healthcare, as a way to organize the ward-based part of the care and cure process. Despite an increased emphasis on patient participation, there has been limited research exploring physician experiences of actually applying these principles to the ward round.

Aim: To explore physician experiences after changing to a patient-centered and team-based ward round, in an internal medicine department at a Swedish mid-size hospital.

Methods: Qualitative exploratory case-study. Semi-structured interviews with 13 physicians (six consultants, three residents, four interns) have been carried out. All interviews have been transcribed and analyzed by qualitative method.

Results: The traditional relationship of superiority and subordination, embodied by the patient lying down in bed and the physician standing over the bed, was one essential change in the new ward round. Physicians experienced that less hierarchical relationships with patients, combined with working in a multi-professional team, contributed to betterinformed clinical decisions, fewer follow-up questions from patients, and increased professional fulfilment. However, physicians also experienced that their autonomy was being reduced, and there was uneasiness about exposing potential knowledge gaps in front of others.

Conclusions: This qualitative study of physician experiences finds that patient-centered and team-based ward rounds is a fertile development journey forward. Also important to notice are the seemingly new and paradoxical findings that despite the introduction of the "right" ward round structure, negative experiences emerged as unwanted side effects to the positive experiences reported. It could be beneficial for leaders in healthcare (both managers and physicians) to consider these results to facilitate future ward round initiatives.

\section{Key words}

Physician, Autonomy, Patient-centered, Team-based, Ward round, Multi-professional, Healthcare management

\section{Background}

Rounding has long traditions within hospital-based healthcare, as a way to organize the ward-based part of the care and cure process, i.e. examination, diagnosis, treatment and follow-up of the patients' care and treatment plans ${ }^{[1]}$. Although 
rounding is conducted in different ways, according to individual choice and institutional tradition, the round serves many common and practical purposes, including acquisition and dissemination of information, education of students and patients, and collaborative discussions of diagnosis, treatment and care plans ${ }^{[1,2]}$.

Professional bodies ${ }^{[3]}$ and healthcare authorities ${ }^{[4]}$ agree about the need to increase patient participation to make the patient the center of attention, empowered in his or her own care ${ }^{[5-7]}$. A variety of methods have been developed to meet these objectives, however Kirkpatrick and colleagues ${ }^{[2]}$ argue that there is limited knowledge about actually applying these principles to ward rounds. This is echoed by Launer ${ }^{[8]}$ who states that methods for running ward rounds effectively and ethically have been given very little attention. Caldwell ${ }^{[9]}$ claims that ward rounds need the same focused attention as the most expensive technology or complex drug treatment. The benefits to quality, safety, effectiveness, efficiency and staff satisfaction would be enormous, and patients would truly benefit as well.

Ward rounds are present in almost all hospital settings and there are research initiatives focusing on many different aspects of round development, for example structured interdisciplinary rounding lowered the rate of adverse events ${ }^{[10]}$, and multidisciplinary rounding reduced length-of-stay for hospitalized patients ${ }^{[11]}$ as well as improving core quality measurements ${ }^{[12]}$. Physician-patient communication in single-bedded versus four-bedded hospital rooms differed with patients asking more questions and making more remarks in single-bedded rooms and physicians showing more empathic reactions ${ }^{[13]}$. Patient-nurse-physician interaction analysis during ward rounds indicated there was a dyad between physician and patient with the nurse having limited inclusion ${ }^{[14]}$ and family-centered multidisciplinary rounds enhanced staff satisfaction in pediatrics ${ }^{[15]}$.

There is also ward related research exploring patient perspectives. One study about information-giving across literacy levels concluded that irrespective of literacy skills, patients felt unable to access, understand and utilize written health information and instead patients described how they were dependent on the relationship with the doctor ${ }^{[16]}$. Another study about barriers to patient participation during the ward round concluded that several aspects of traditional ward round routines could be improved to enhance the two-way information exchange. In particular it was stressed that all healthcare professionals need to acknowledge the patients' right to participate ${ }^{[17]}$. Why some patients are reluctant to collaborate with physicians about their choices in healthcare was explored by Frosch and colleagues. Patients in their study voiced a strong desire to engage in shared decision-making about treatment options. However, they argue that conforming to socially sanctioned roles where physicians can be authoritarian, and the fear of being categorized as "difficult" prevent patients from participating more fully in their own healthcare ${ }^{[18]}$.

Although evidence is growing that effective working from multidisciplinary team-rounding improves patient outcomes ${ }^{[4]}$, there is insufficient evidence to guide successful changes in ward rounds ${ }^{[19]}$. A recent Cochrane intervention review with the focus on interprofessional collaboration ${ }^{[20]}$, including two round studies, concluded that interprofessional collaboration can improve healthcare processes and outcomes, but that more studies are needed to draw generalizable inferences. Studies including qualitative methods were recommended by Cochrane to provide further insights ${ }^{[20]}$.

Gosfield and Reinertsen ${ }^{[21]}$ claim that hospital leaders need to better understand the physicians' perspective related to quality, since physicians are in a powerful position to stop or severely hinder change initiatives they do not see will benefit patients and/or themselves. Snell et al. ${ }^{[22]}$ argue that more research is needed, focusing on the context and the specific needs of the medical profession, to better understand what physicians themselves consider as hinders and enablers for improvement work, like changing the ward round. Fiddler and colleagues ${ }^{[19]}$ argue that despite an increased awareness about the importance of understanding the experiences of those involved in a change, research is still sparse to investigate how professionals view changes to ward rounds. Our study explored physician experiences after changing the ward round in an internal medicine department at a mid-size hospital in Sweden. The new round was patient-centered and team-based. 


\subsection{The new ward round}

The new round originated from conversations within and amongst the professional groups at the internal medicine department. The initiative was seen as a larger development project and was supported by the head of the department. The change process was managed without any external resources.

The new ward round was based upon three principles: (1) increasing patient integrity, (2) minimizing informationhandovers between health professionals, and (3) finalizing all tasks related to each patient.

In order to increase patient integrity, special rounding rooms were established. The rounding rooms were set up with chairs facing each other to enable patient and caregivers to meet each other on the same level, whenever medically possible.

To be able to minimize information-handovers and also to finalize all tasks related to each patient, care teams were formed. The team consisted of senior and junior physician, registered nurse and assistant nurse. The junior physician was scheduled for the full week at the ward and the senior physician was scheduled Monday, Wednesday and Friday. There were three teams for every ward and each team shared a small office.

The care team would meet briefly at a pre-defined time every morning, to plan the day and prioritize which patients should be rounded and what time to start rounding. Patients were prioritized based upon medical criticality and progress in the care process. This means that not every patient was rounded every day. Instead patients were rounded for a cause, for example just admitted, change of patient condition, results of lab-tests, patient could soon return home. The process was managed by use of a whiteboard and patients were given a color code in relation to priority. Patients due for discharge were managed after the brief prioritization team meeting, and before the actual rounding started.

Each care team documented their findings and conclusions in the electronic medical record after every patient meeting. Before bringing the next patient in, the team strove to finalize all tasks related to the previous patient.

Rounding went from loosely structured, where traditionally each individual physician decided how to round, to a defined team-based work plan as outlined above. The table outlines key differences comparing the previous round with the new round.

Table. Comparisons between previous and new round

\begin{tabular}{lll}
\hline & Previous round & New round \\
\hline Frequency & Every day & When there was a special cause \\
Location & 4-bed ward room & Special rounding room \\
Patient position & Lying in bed & Sitting in chair (whenever possible) \\
Physician position & Standing next to bed & Sitting in chair \\
Documentation & Each health professional & Team documentation \\
Structure & Loose, physician decides & Tight, pre-defined work plan \\
\hline
\end{tabular}

\subsection{Aim}

To explore physician experiences after changing to a patient-centered and team-based ward round, in an internal medicine department at a Swedish mid-size hospital.

\section{Methods}

\subsection{Design}

This study was a qualitative interview based case-study and had an exploratory design. 


\subsection{Setting}

This study was carried out at an internal medicine department at a regional mid-size emergency-hospital in west Sweden, and was part of a four-year (2010-2014) interactive research and development project concerning trans-professional development processes in healthcare organizations. Earlier findings from this project have been reported ${ }^{\text {[23, 24] }}$.

The hospital provided specialist care in general and orthopedic surgery, internal medicine, geriatrics, and psychiatric care, with a total of 200 beds, 1,500 employees and care responsibility for an area with 118,000 citizens. The internal medicine department had about 140 employees of whom 46 are registered nurses, 30 assistant nurses and 47 physicians. The department had about 4,000 inpatients a year, whereof about $85 \%$ was admitted via the emergency. The department was divided into two wards with 25 beds each, with an average length of stay around four days. Each ward had three single rooms available for the most critical ill patients and three rooms with double occupancy. The remaining beds were available in 4-bed ward rooms. The ward patients were equally divided between men and women with an average age around 67 years. The department catered for both emergency and chronic patients with a spectrum of diseases related to hormone-based, intestinal, hematology, cardiac and pulmonary disorders.

\subsection{Participants}

Purposeful sampling ${ }^{[25]}$ was used as strategy when inviting physicians to participate. We tried to find a variety of physician voices with rich, divergent information and sought physicians who were positive as well as those who were negative to the round initiative. We also wanted variation in the physicians' gender and seniority. Thirteen physicians were interviewed of whom six were very experienced physicians (three male and three female consultants), three were experienced physicians (three female residents) and four were less experienced (two male and two female interns).

\subsection{Data collection}

The choice was made to use qualitative research interviews since they can be seen as a way to understand the world as seen by the interviewees ${ }^{[26]}$. The interview guide had open-ended questions to allow probing into aspects that emerged during the interview. Examples of interview questions are: "How would you describe your experiences from working in the new round?" "How would you describe what the core elements are in the new round?" One assumption behind the design of this type of question is that people act according to their understanding of the world ${ }^{[27]}$, and although what people present in interviews is simply the results of their perception, that perception does in fact inform their actions ${ }^{[28]}$.

The interview process was set up in cooperation with the development secretary at the internal medicine department. Data was collected between December 2011 and March 2012, that is, 12-15 months after the new round was introduced. All interviews were conducted face-to-face using local conference room facilities on the hospital site, and were digitally recorded. The first author carried out seven of the interviews and one researcher from the larger development project carried out six of the interviews. Each interview lasted between 45 and 120 minutes, with an average timespan of around 80 minutes.

\subsection{Data analysis}

The analytical process followed principles for qualitative analysis as outlined by Miles and Huberman ${ }^{[29]}$. All interviews were transcribed verbatim and each interview was read and then condensed, focusing on physician experiences when working according to the new round. Empirical dimensions where formed within each interview and similarities across interviews were combined into themes. The analytic process continued in this reiterative process until data reached a point of convergence where eight themes encompassed most of the material. Alternative interpretations were continuously looked for in critical reflections.

To cater for a multifaceted interpretation of the empirical data, the analytical process involved a trans-disciplinary team of four senior researchers, in addition to the first author. Each of them read selected interviews and in face-to-face meetings 
presented their own and challenged each others' emerging dimensions and themes. The researchers had complementary experiences to the first author who is a doctoral candidate in medicine with a professional background from management positions in healthcare and high-tech, trained in group relations theory and educational background from industrial engineering and management. One is an experienced physician and associate professor in medicine, one an experienced nurse and professor in healthcare pedagogics, one a senior lecturer in healthcare pedagogics and one a professor in business administration with experience from healthcare research. Members of the research team had extensive experience of qualitative analysis.

Semi-finished results were reiterated back in two sessions during the medicine department development days. The resulting exchange was rich, the emerging findings seemed to make sense and be useful for the practitioners and no additional aspect was brought up.

\subsection{Ethics}

The overall aim of the Swedish law concerning ethical application for research relating to humans is to protect the individual and make sure that human values are respected, while at the same time the law tries to minimize applications from unproblematical projects ${ }^{[30]}$. The risk for harm to individuals participating in this research is low and it is not a very sensitive topic, thus the project does not fulfill the criteria justifying an application to the ethical board. However, the ethical demands for qualitative research such as informed consent, confidentiality, the consequences of the study and role of the researchers, have been considered and followed.

\section{Results}

The eight themes emerging from the analysis of physician interviews are presented below. Quotes are provided to give the reader an empirical experience of physician voices. Each physician has a random number between 1 and 13 to prevent identification but still enable the reader to follow different physician voices in the text.

\subsection{Relational change promoted communication}

The traditional relationship of superiority and subordination, embodied by the patient lying down in bed and the physician standing over the bed, was changed and physicians experienced how patients now also brought up social dimensions of their illness and talked about their expectations and anxieties:

"...we can talk about things that are really important for the care process and for the patient, like what he/she would like to be able to do when leaving the hospital. Things that just never came up before.” Resident (2).

By having the patient meet the care team in a special rounding room, and whenever medically possible sitting on a chair facing the physician, physicians experienced that hierarchical distance was reduced. A less hierarchical relationship between patient and physician was thus made possible, which made their communication exchange more like an ordinary conversation:

"I believe that patient conversations are much better now /.../. It's more beneficial, both for me and for the patient I would say. We could carry on more on an equal level. I sit down and the patient does as well, I no longer lean over the patient. Just such a simple thing makes a major difference for the way we talk to each other.” Resident (2).

Physicians experienced that the new round enabled patients to come across much more as persons, subjects and human beings compared to experiences from the previous round:

“...you really see the patient or at least the possibility is there for seeing the patient.” Intern (8). 
Physicians experienced that this change has made it possible for round conversations to include other aspects than the traditional bio-medical dimensions:

“...you touch on topics that are more private, sensitive things since the round structure is so different. I mean, when you are in a room with 4 beds doing the traditional round there is a bio-medical-technical jargon, focusing mostly on what the latest test results showed." Consultant (1).

\subsection{I ncreased understanding}

Physicians reported the new way of rounding as supporting a learning perspective for physicians, patients and other staff. One physician described that the way patients moved and how much support they needed to come to the dedicated rounding room provided valuable new information, leading to better-informed care and treatment decisions. The physician, somewhat jokingly, made the comment that we all know that once we leave the bed in the morning we start to feel more capable, so maybe the traditional way of rounding has made patients actually look less healthy in the eyes of the physicians.

Physicians expressed the view that patients now seemed to understand more about their care and that follow-up questions from patients (and next-of-kin) after the round had decreased. Meeting the care team in a special room made it easier for the care team to explain the care process to patients and provided a supportive arena for patients to ask questions. Physicians also expressed the opinion that there was increased understanding among nurses and assistant nurses when participating in the round conversation, enabling them to respond to more questions from the patients without referring back to the physician:

“...I have heard from the night staff that they receive much fewer questions. Patients are better informed. Much fewer questions like: What is it really I have, Why am I here! What are you going to do to me next? Those night-agony questions seem mostly to have disappeared.” Consultant (3).

\subsection{I mproved patient integrity but a need for new conversation strategies}

Physicians appreciated the improved integrity for patients. An experienced consultant said that he/she was no longer comfortable holding a patient conversation in a room with three other patients overhearing it:

"I have been doing the traditional rounds for about 16 years. I recently noticed that I have a hard time going back to doing the round in a 4-bedded room. My patient conversation is hampered when I know there are three more patients listening. I cannot really grasp how we previously dared to speak about sensitive and private issues in front of other patients." Consultant (13).

The new round conversation made deeper and more thorough information-gathering possible, also including the social dimensions of the illness. Physicians found this both beneficial and legitimate for the care process, but the new round conversations with the patient also introduced time-related challenges for them. Previously, with the patient in bed, one way to manage time constraints during the round was for the physician to start walking towards the next patient, thus effectively cutting off any further questions from the first patient:

"When rounding in a 4-bed ward room, each patient is aware that they have limited time in some way. So they don't open up much. But when you meet them in a special room, patients start to expand their story.” Resident (2).

Now, with the patient sitting in a chair in a special round room, the previous strategy for managing time constraints was no longer functional. Physicians had to establish another way of working to manage the limited time for each patient: 
"Patients always want to expand their story. Physicians mostly want to reduce their involvement with each patient/.../it is of course easier for the physician to reduce his/her involvement with a patient lying in bed, because then the power structure is in favor of the physician. You can very easily close down a conversation and do the examinations as you like. Once you have let the patient get up and face you, that option is no longer valid.” Consultant (1).

\subsection{Teamwork improved clinical quality}

Physicians emphasized the importance of meeting patients together with other team members since information from the other care professionals was beneficial for making well-grounded decisions. Physicians stressed how this interprofessional cooperation created a foundation for good care:

“Teamwork really makes things easier. One knows the plan, your task, my task, today’s tasks. Patient status, have we got a good grip on things?” Intern (8).

When all have heard the same things the risk for misunderstandings and the need for reporting were reduced. By having the care-team around the patient gather in the round room preconditions were established that facilitated an increased understanding of patient perspectives as well as the agreed clinical steps. When the team around the patient was participating in the round conversation the risk of information loss from reporting between different professional groups was reduced:

"I think it is very valuable to be able to bring the patient to a special room and just sit down and talk to them, and to have the nurse and the assistant nurse there with me. Everyone hears the same thing and we avoid the never-ending reporting." Resident (12).

Physicians experienced that their understanding about their patients grew more complete. This enabled them to make more informed decisions, potentially leading to better quality of care, and aspects a patient could have mentioned to a nurse or an assistant nurse have gotten a natural way of coming to the knowledge of the physician during the team-based round:

"We meet the patient together and I say my thing and the nurse says her thing, and it becomes easier to get the full picture. There may be issues they have talked with the patient about before. The nurse can help the patient communicate by simply saying, well last night we talked about this concern.” Resident (7).

Physicians reported that close cooperation with nurses and assistant nurses added to care safety in at least three ways. Firstly, the patient and relatives understood more of the care process leading to better compliance from the patient. Secondly, the nurse and assistant nurse had a deeper understanding about patients' individual care plans leading to better follow-up. Thirdly, since everyone had heard what was planned a supportive structure with mutual reminders emerged within the care team leading to internal compliance, really doing those things that they and the patient had together decided were most important to do:

"Everything is said in the same room and everyone has heard it. Perhaps the assistant nurse now realizes why it is really important for the patient's wellbeing to get out of bed as soon as possible. Or perhaps a nurse asks me after a while why I have not written a certain X-ray order, when I had simply forgotten. Care becomes safer in many ways through this way of working." Consultant (13).

Some physicians also expressed disappointment that nurses and assistant nurses did not take enough space during the round conversations to really ensure that their perspectives were heard:

"This structure also requires you to really speak up if you have something or think about something during the round conversation. Sometimes I think the nurses and assistant nurses are too passive.” Consultant (11). 


\subsection{Sharing office space - pros and cons}

Sharing office space was something physicians experienced as both disturbing and beneficial. Previously, with separate offices, they often experienced the need to search for the nurse to share decisions and information. When sharing offices, there was a pre-established forum where information was shared, and they appreciated always being able to find each other.

Physicians experienced however that the benefits of sharing office space with other care professionals came with the price of limited quiet-space for them to ponder patient issues:

"Our building is not really constructed to cater for this set-up. This was my strongest opposition: we do not have office space that works for this round concept.” Consultant (4).

Physicians reported positive experiences relating to working more closely together, but also challenges. To enable this type of close teamwork to function physicians needed to adjust to the other care professionals. It seemed that physicians had neither realized nor experienced anything like this before:

“....it increases your understanding for the other professionals' work situation. But that is also the problem. When working this close together one must adjust to each other.” Consultant (1).

\subsection{Reduced physician autonomy}

Previously there had been no uniform method for carrying out the round. Physicians experienced that the new well-defined round reduced their autonomy, since individual physicians could no longer carry out the round as they found suitable. This might relate to issues like what time the team should start its priority work, but also to more fundamental matters like not rounding each patient every day:

"The new round structure is a very well-defined system, which does not really give me leeway to determine how to work. And I think it is well known that doctors are very different, work very differently and throughout the years have rounded in very different ways. And here and now we are all supposed to fit into the same round model. And that perspective might not really suit everybody; comply, do it this way, period!” Consultant (10).

Reduced autonomy was a negative aspect some of the senior physicians stressed more than the others. It became apparent that there were two opposing perspectives as to how senior physicians perceived the round process. In particular there were major differences relating to the way patient interaction was looked upon. One perspective was focusing on thorough preparation before the round, examining most or all written documentation and striving to have a clear hypothesis, before meeting the patient:

"We need to get a good grip on the situation. And the core source for that is a thorough look at the written documentation. Not only the last entries but case history, lab, x-ray, you name it! Also we need to check with the patient. Gather all the data and then act!" Consultant (4).

The other senior physician perspective was focusing on patient interaction, striving to limit any predetermined hypothesis, and instead paying much attention to patient conversations during the ward round:

"For me there is a point in meeting the patient without reading the documentation, without any pre-understanding. I focus mostly on the meeting with the patient to get a solid conversation and resulting anamnesis.” Consultant (1).

\subsection{Exposing potential knowledge gaps}

In the previous round physicians had established ways to manage questions to which they did not know the answers. With the patient in bed it was possible to move on, referring to time pressure or another objective reason, and after the round the 
physician had time to consult another colleague or read up on the matter at hand, and later come back to the nurse or the patient with the response. This old way of handling "tricky questions" did not work in the new round. Senior physicians experienced a new risk of "losing face" by exposing potential knowledge gaps in front of the others in the round room:

"The round conversations are carried out in front of others, colleagues and nurses, which exposes me much more. It may expose my limited knowledge, since a patient may ask something I don't know. Then my colleagues and the patient notice that I don't have that knowledge.” Consultant (1).

\subsection{I ncreased professional fulfilment}

Physicians experienced an increased sense of professional fulfilment working on the new round. There seemed to be an appreciation that the new round facilitated working closer to the ideals and clinical principles physicians were striving towards. The new way of meeting patients was especially emphasized:

"Yeah, some of the rounds now are really magic. Of course it depends on whom you are working with, it always does. But with our previous way of rounding we never ever had magic rounds. Previously we did not have any patient meetings with quality.” Consultant (3).

Another dimension appreciated by physicians was an ever-present aspect of learning and developing. Partly this involved an increased knowledge base for nurses and assistant nurses through their participation in the round conversations, but physicians also reported that their own development benefitted from the richer clinical encounters with patients:

"This new way of rounding is a major improvement. Patient-centered of course, but also employee-centered, since we all learn and develop within this new team-based structure. Patients, nurses, assistant nurses and I as a physician get a more solid sense of coherence.” Resident (2).

Physicians related that the improved contact with nurses and assistant nurses also constituted an important change. A new "we-feeling" seemed to be becoming established from working close to each other, and simply starting to learn their names was an appreciated aspect. Physicians also experienced better understanding of what the other care professionals did. This made it easier to work together and fueled a fulfilling sense of mutual trust:

“....is has been said that we are to work in teams to cater for the patients better. But funnily enough our own work tasks also become easier once we start to know each other better, who I am working with, how they function and what they are good at... and bad at. And of course what I am good and bad at. / .../ The overall climate has improved, it seems to be better when we go and have a fika together.” Intern (8).

Patients' positive feedback also contributed to the increased sense of satisfaction. Feedback was especially appreciated from patients who themselves were working, or had worked as healthcare professionals, and as such had experienced the traditional round themselves:

“... many patients have said that this is really good. And also we have had care professionals as patients who have commented. One senior physician and a couple of senior nurses have provided very positive feedback. This senior physician, he was a surgeon, he felt ashamed of never rounding in the way that we now did, during his professional life.” Consultant (3).

\section{Discussion}

The present study builds an empirically-based understanding about physician experiences working according to a patient-centered and team-based ward round. Physician experiences gravitated around the changed relationship between 
physicians and patients. A less hierarchical relationship, combined with working in a predefined multi-professional team (senior physician, junior physician, a nurse and an assistant nurse), was experienced as contributing to better-informed clinical decisions, fewer follow-up questions from the patients, and increased professional fulfilment. Physicians expressed a need to evolve communication skills since their traditional way of managing bedside conversations was no longer functional with the patient sitting in a special rounding room facing the physician. However, physicians also experienced their autonomy being reduced by the new predefined rounding structure, and there was uneasiness about exposing potential knowledge gaps in front of others. These two last themes were primarily experienced by senior physicians.

Physicians in our study reported that their changed relationship with patients was one of the most important aspects of the new round. The less hierarchical relationship made interactive communication possible, which in its turn supported physicians' continuous striving towards better clinical decisions, quality of care and better ways to inform patients. The importance of the interpersonal exchange for quality of care was described by Donabedian ${ }^{[31]}$ who argued that it is through interpersonal exchange that patients communicate information necessary for arriving at a diagnosis, as well as preferences necessary for selecting the most appropriate care. The interpersonal exchange is also where the physician provides information about the nature of the illness and its management and motivates the patient to active collaboration in care. Donabedian ${ }^{[31]}$ concluded that the interpersonal process is the vehicle by which technical care is implemented and on which its success depends. Sweet and Wilson ${ }^{[32]}$ make a similar point, twenty odd years later, that the problem with the hospital round is that its traditional style has remained rather impersonal or objective, focusing more on the disease than on the sick person. This is echoed by the UK Royal College of Physicians and the Royal College of Nursing who in their recent ward round guidelines ${ }^{[4]}$ emphasized that healthcare professionals should not underestimate the importance of interaction on rounds, from the patient's perspective. The relationship between caregivers and patient is also what the October 2012 Lancet editorial about the ward round focuses on as they claim; "if you do not communicate with your patients clearly, and do not treat your patient in a dignified manner, you are not providing even the bare minimum of health care" ${ }^{333]}$. There seems to be conceptual understanding and consensus about the importance of patient-centeredness, but applying it to ward praxis is, as our results show, not a straightforward linear process. Our results resonate with Malterud ${ }^{[34]}$ who describes the task of physicians as two-fold: to understand the patient and to understand the disease. Findings in our study are in line with Malterud's argumentation that patient-centered change efforts are not quick fixes partly since there is a well-tried clinical method for understanding diseases, but no equivalent method for understanding patients.

In our study physicians stated that a less hierarchical relationship with the patient was an important result that followed from the new round. This change seems to have come about from the combination of three separate, but interrelated, interventions: firstly, moving from a very hierarchical structure - with physicians standing and patients lying down towards a more equal perspective where both sit in a chair facing each other; secondly, using a special room allowing privacy during the round conversation; and thirdly, having the physicians meet the patient together with the nurse and the nurse assistant. Physician-patient communication in single-bedded versus four-bedded hospital rooms was studied by van de Glind and colleagues ${ }^{[13]}$. They concluded that single rooms seemed to contribute to physician-patient communication in a positive way since patients asked more questions and affective reactions from physicians were more frequent in single rooms. They continued their line of argument by assuming that patient understanding of the health and care process is likely to be positively affected. Our study resonates with their findings and also substantiates their assumption about increased patient understanding. Previous studies have reported that interdisciplinary rounding reduced medical errors ${ }^{[20]}$ and improved the quality of care for hospitalized patients ${ }^{[11]}$. Our study has not measured medical error, but our findings from physician interviews indicated that clinical quality was positively impacted in a number of ways.

In our study the benefits of working in defined multi-professional teams were appreciated by the physicians, while at the same time it was a new experience for physicians to adapt to other professionals. This somewhat paradoxical finding is well in line with 2012 research by Bharwani and colleagues ${ }^{[35]}$. When researchers followed four different medical 
rounding teams it showed that caregivers had in all instances formed working groups, rather than working teams. Participants consistently exhibited parallel interdependence (individuals working alone and assuming their work would be coordinated with other caregivers) rather than reciprocal interdependence (individuals working together to actively coordinate patient care), the hallmark of effective teams ${ }^{[35]}$. In our study physicians noted the challenge involved in evolving from a position as autonomous physicians into a conforming and responsive team-player, but as far as we can conclude from our interviews, the praxis outcome at the wards actually exhibited signs of reciprocal interdependence, indicating well-functioning teamwork.

Physicians in our study experienced a need for improved strategies to manage patient conversation when working according to the new round. The less hierarchical setting accentuated this issue since patients, as intended, naturally expanded their stories when sitting up in a chair compared to lying down in bed. This aspect builds on what Levinson and colleagues ${ }^{[36]}$ reported when studying physician communication skills for patient-centered care, where they argued that practicing physicians have typically not received any structured training related to communication since they left medical school.

Physicians reported large variation with regard to their individual experiences of time consumption in the new round. This is in line with Stickrath and colleagues ${ }^{[37]}$ who reported great heterogeneity and large time variation between individual physicians, rounding on average nine patients in two hours, approximately 14 minutes per patient. A high-quality ward round, following the Caldwell considerate checklist, took 12 minutes per patient, with considerable variation ${ }^{[38]}$. Large variation between physicians time-motion patterns during walking rounds was also reported using real-time location systems ${ }^{[39]}$. Research showed that single-room rounding took longer time compared to rounding four-bedded rooms ${ }^{[13]}$. The new rounding concept, as reported in our study, had addressed the likely increase in time by only rounding patients when there was an explicit cause (new lab results, change of medication, check-up etc.), while previously all patients were to be rounded every day. However we do not have any time measurement to be able to comment on actual time consumption.

Our study outlined that physicians experienced a reduction of autonomy working in the new round. Previously, each physician decided how the round was to be carried out and other health professionals adapted to this. This seems to be in line with recent studies. Gawande ${ }^{[40]}$ argued that traditionally every clinician had his or her way of doing things. An observational study of general medicine rounds found great heterogeneity in the composition of rounding participants, the number of patients discussed during rounds and the activities performed ${ }^{[37]}$. Large time variations between physicians rounding the same ward may indicate distinct rounding styles ${ }^{[39]}$. Healthcare has a unique and complex relationship to the autonomy of its individual actors where human virtue is seen as the basis for safety and human incompetence as the source of risk ${ }^{[41]}$. However, reduction of physicians' autonomy seems neither to be a uniquely Swedish nor a uniquely local hospital phenomenon. In a very recent article Halpern and colleagues ${ }^{[42]}$ reported how autonomy has been stepwise reduced in the internal medicine residency programs since the 1970s. At the same time physicians are trained to feel personally responsible and therefore place great value on their individual autonomy in care decisions ${ }^{[21]}$. Arnetz ${ }^{[43]}$ argued that due to the many healthcare reforms around the world there is an accelerating need for physicians to reconsider their traditional role.

Our results showed that working in a predefined rounding structure increased physician professional fulfilment, but in a paradoxical way the new round also reduced physician autonomy and introduced a new risk of losing face. Negative experiences relating to reduced autonomy were expressed by some of the senior physicians. We have not yet any clear understanding why the new round triggered such different responses among equally experienced senior physicians. However we associate with the perspective by Stacey ${ }^{[27]}$ that an organizational change is also a deeply personal change for an individual, and that the individual and the group are paradoxically formed by and forming each other, at the same time. One plausible way to further understand the two dichotomies is presented by Dall'Alba ${ }^{[44,45]}$ who argued for two ways of enacting practice where one is more bio-medically centered with focus on diagnosing and treating disease, and the other 
having more of a patient-centered orientation caring for the person who is ill. Tension between these two ways of enacting practice has long been evident in the practice of medicine ${ }^{[44]}$. How these differences of enacting practice are impacting clinical outcomes is up to debate, and we have not seen any publications measuring patient-related outcomes in an internal medicine setting. However Birkmeyer and colleagues ${ }^{[46]}$ have recently assessed clinical skill for a group of senior physicians, and also linked clinical skill to clinical outcomes. Their study, amongst fully trained experienced surgeons, showed a wide variation in technical skill. Patients treated by surgeons with high skill ratings compared with patients treated by surgeons with low skill ratings were at least twice as likely to die, have complications and be readmitted to the hospital after discharge ${ }^{[46]}$. This cannot easily be translated into internal medicine, but it is interesting how Birkmeyer and colleagues show a large variation amongst senior surgeons, and argue that surgeon clinical skill is directly related to clinical outcomes. The extra challenge at hand for senior physicians, having spent many years doing their individual praxis, is also addressed by Gosfield and Reinertsen ${ }^{[21]}$ who outline an argument (spoken or unspoken) from physicians about proposed change impacting patient care: “If I'm doing it this way now, what I'm doing can't be bad, because I'm a good doctor, and I'm trying hard to do what's best for my patients".

In our study senior physicians also experienced an additional risk of exposing potential knowledge gaps in front of others. There seemed to be a cultural predisposition that a senior physician always knew or would come up with the answer, and it seemed to be a workplace dimension that senior physicians had to cope with. This is in line with research carried through in the early 1990s ${ }^{[47]}$ which after in-depth interviews with eleven physicians, reported how profound emotional distress was experienced if physicians had made a mistake. These physicians also admitted that fear of humiliation, litigation or punishment had prevented some of them from talking about their feelings with other physicians. Another perspective could relate to the argument from Mork and colleagues ${ }^{[48]}$ that experienced physicians might be uncomfortable changing clinical practices since power relations between senior and junior physicians may be substantially reconfigured when introducing new practices.

Since senior physicians have the positional power to stop or severely hinder change initiatives they do not see will benefit patients and/or themselves ${ }^{[49]}$, both factors mentioned above, admitted by senior physicians, seem important to bear in mind for hospitals looking into future round initiatives. Early acknowledgment from people in charge of an initiative that a change process could impact autonomy, and scheduled forums where senior physicians could talk to each other about how to integrate the new round praxis in their role, is recently reported by Baathe and Norback to be one possible way to work with this challenge ${ }^{[24]}$.

Previously at the internal medicine department there was no uniform method for carrying out ward rounds. It was implicit that each senior physician had his/her own individual way, and the variation was absorbed by the other care professionals. Without any established definition of how to carry out the round, there was no common ground for delivering stringent feedback. Any and all feedback would most likely have been experienced, from both sides, as complaining and nagging. And this might be one of the more fundamental explanations why round praxis in the 21st century, in many hospitals, has not changed much since the 20th century ${ }^{[33]}$.

\section{Strengths and limitations}

One of this study's strongpoints is the rigorous use of a qualitative method for both data gathering and analysis. We have striven to get a diverse group of interviewees' together by use of a variation strategy. The individual interview setting allowed participating physicians to be candid about their experiences, making it possible to accumulate a wealth of data. A potential limitation is inherent in the fact that the analysis of interviews always is a matter of interpretation by the researchers. There is a risk that you see only what you expect to see. However, in our study, to reduce any single researcher's pre-understanding to overpower the individual physician voices, we organized our analytical process with five researchers reading and interpreting the empirical material. Those five researchers had different educational as well as professional backgrounds, including clinical and managerial experiences from Swedish healthcare. The group convened a number of times to compare findings and through conversation worked to reach an interpretation that was true to the 
original transcript, increased mutual understanding and provided overarching resonance. As an additional measure to stay tuned to the clinical reality our study was exploring, semi-finished results were referred back to clinicians in two sessions during their development days. Our preliminary findings seemed to make sense to the practitioners and no additional aspects were brought up.

Another perspective to consider is that the participants come from an internal medicine department at a mid-size Swedish hospital. Thus these findings might not be generalizable outside this context. However, given the degree of communality amongst physicians in the western world, often depicted as one occupational community of praxis ${ }^{[50]}$, we argue that there actually are elements of knowledge coming from this contextually-based study that could be applicable elsewhere. This study has tried to provide a detailed description to facilitate transferability. Our line of reasoning is based upon the assumption that any use of a piece of research is a dynamic act, which is completed if, and only if, someone else can make sense of situations or processes or other phenomena with the help of the interpretations presented in the research text ${ }^{[51]}$.

\section{Conclusions and future research}

This qualitative study has explored physicians' experiences of working according to a patient-centered and team-based ward round. Physician experienced the new round was contributing to better-informed clinical decisions, fewer follow-up questions from the patients, and increased professional fulfilment. Also important to notice are the seemingly new and paradoxical findings that despite the introduction of the "right" ward round structure, previously undescribed negative experiences emerged as unwanted side effects to the positive experiences reported. These negative experiences were primarily emerging from some of the senior physicians' attitude to a reduction of autonomy, and their experience of an increased risk to expose knowledge gaps in front of others, merit additional research. Potential questions one could consider are:

- Since physician's autonomy seems to be impacted, what does a change of autonomy do to the professional identity as a physician?

- How can we better understand the two dichotomies that emerge from equally senior physicians in response to this new round structure?

- What experiences do nurses and assistant nurses have of working according to a patient-centered and team-based ward round?

- What experiences do patients have of patient-centered and team-based ward rounding?

Round praxis in many hospitals is described as not having changed much in the last century. However, things are seemingly starting to evolve. Physicians' experiences of a team-based and patient-centered round initiative, as reported in this study, suggest this development journey is a fertile way forward. This study also adds knowledge to facilitate future initiatives about changing a clinical praxis that is one of the most well-established in hospital care, ward rounding.

\section{Authors' contributions}

FB: Study design, data collection, data analysis, and writing the manuscript;

AL: Data analysis and consistency of the manuscript;

GA: Study design, data analysis, and consistency of the manuscript;

LE: Study design, data analysis, and consistency of the manuscript;

KN: Study design, data analysis, and consistency of the manuscript.

\section{Competing interests}

The authors declare they have no competing interests. 


\section{Acknowledgements}

Åsa Lindgren was a great asset during the interview process. Jointly we also produced early reflections from the interviews, which were presented back to the department. Lars-Erik Norbäck deserves much appreciation, having been the project leader of the larger trans-disciplinary and interprofessional research initiative this study emanated from. Financial support has been received from the Swedish innovation office, Vinnova as well as Region Västra Götaland. Employees at the internal medicine department at Kungälv hospital have been very generous with their time and in sharing their clinical experiences. Without you all, this study would not have been accomplished!

\section{References}

[1] O'Hare JA. Anatomy of the ward round. European Journal of Internal Medicine. 2008; 19(5): 309-13. http://dx.doi.org/10.1016/j.ejim.2007.09.016

[2] Kirkpatrick JN, Nash K, Duffy TP. Well rounded. Arch Intern Med. 2005; 165(6): 613-6. Epub 2005/03/30. PMID: 15795335. http://dx.doi.org/10.1001/archinte.165.6.613

[3] Royal College of Physicians, Royal College of Nursing. Ward rounds in medicine: principles for best practise. RCP London. 2012.

[4] Your obligation to make the patient participate. Handbook for carecompanies, managers and careprofessionals (Original Swedish language: Din skyldighet att informera och göra patienten delaktig. Handbok för vårdgivare, chefer och personal), (2010, Third edition, Jan 2012).

[5] Ekman I, Swedberg K, Taft C, Lindseth A, Norberg A, Brink E, et al. Person-Centered Care - Ready for Prime Time. European Journal of Cardiovascular Nursing. 2011; 10(4): 248-51. http://dx.doi.org/10.1016/j.ejcnurse.2011.06.008

[6] Charon R. Narrative medicine: honoring the stories of illness. New York: Oxford University Press. 2008.

[7] Launer J. Doing the rounds. QJM. 2003; 96(4): 321-2. http://dx.doi.org/10.1093/qjmed/hcg047

[8] Launer J. What's wrong with ward rounds? Postgraduate medical journal. 2013; 89(1058): 733-4. Epub 2013/11/19. PMID: 24243984. http://dx.doi.org/10.1136/postgradmedj-2013-132472

[9] Caldwell G. The importance of ward rounds. Presentation to NHS Emergency Care Intensive Support Team. Available from: https://www.dropbox.com/s/tzep6wa8sw4ik0b/The\%20Importance\%20of\%20Ward\%20Rounds\%20plus\%20appendices.pdf: 2013 (accessed 26 May 2014). Report No.

[10] O'Leary KJ, Buck R, Fligiel HM, Haviley C, Slade ME, Landler MP, et al. Structured interdisciplinary rounds in a medical teaching unit: improving patient safety. Arch Intern Med. 2011; 171(7): 678-84. Epub 2011/04/13. PMID: 21482844. http://dx.doi.org/10.1001/archinternmed.2011.128

[11] Begue A, Overcash J, Lewis R, Blanchard S, Askew TM, Borden CP, et al. Retrospective Study of Multidisciplinary Rounding on a Thoracic Surgical Oncology Unit. Clinical Journal of Oncology Nursing. 2012; 16(6): E198-E202. PMid: 23178362. http://dx.doi.org/10.1188/12.CJON.E198-E202

[12] O'Mahony S, Mazur E, Charney P, Wang Y, Fine J. Use of multidisciplinary rounds to simultaneously improve quality outcomes, enhance resident education, and shorten length of stay. J Gen Intern Med. 2007; 22(8): 1073-9. Epub 2007/05/09. PMID: 17486384. http://dx.doi.org/10.1007/s11606-007-0225-1

[13] Van de Glind I, van Dulmen S, Goossensen A. Physician-patient communication in single-bedded versus four-bedded hospital rooms. Patient Education and Counseling. 2008; 73(2): 215-9. http://dx.doi.org/10.1016/j.pec.2008.07.004

[14] Weber H, Stöckli M, Nübling M, Langewitz WA. Communication during ward rounds in Internal Medicine: An analysis of patient-nurse-physician interactions using RIAS. Patient Education and Counseling. 2007; 67(3): 343-8. http://dx.doi.org/10.1016/j.pec.2007.04.011

[15] Rosen P, Stenger E, Bochkoris M, Hannon MJ, Kwoh CK. Family-centered multidisciplinary rounds enhance the team approach in pediatrics. Pediatrics. 2009; 123(4): e603-8. Epub 2009/04/02. PMID: 19336351. http://dx.doi.org/10.1542/peds.2008-2238

[16] Shaw A, Ibrahim S, Reid F, Ussher M, Rowlands G. Patients' perspectives of the doctor-patient relationship and information giving across a range of literacy levels. Patient Education and Counseling. 2009; 75(1): 114-20. http://dx.doi.org/10.1016/j.pec.2008.09.026

[17] Swenne CL, Skytt B. The ward round - patient experiences and barriers to participation. Scandinavian Journal of Caring Sciences. 2014; 28(2): 297-304. http://dx.doi.org/10.1111/scs.12059 
[18] Frosch DL, May SG, Rendle KAS, Tietbohl C, Elwyn G. Authoritarian Physicians And Patients' Fear Of Being Labeled 'Difficult' Among Key Obstacles To Shared Decision Making. Health Affairs. 2012; 31(5): 1030-8. http://dx.doi.org/10.1377/hlthaff.2011.0576

[19] Fiddler M, Borglin G, Galloway A, Jackson C, McGowan L, Lovell K. Once-a-week psychiatric ward round or daily inpatient team meeting? A multidisciplinary mental health team's experience of new ways of working. International journal of mental health nursing. 2010; 19(2): 119-27. Epub 2010/04/07. PMID: 20367649. http://dx.doi.org/10.1111/j.1447-0349.2009.00652.x

[20] Zwarenstein M, Goldman J, Reeves S. Interprofessional collaboration: effects of practice-based interventions on professional practice and healthcare outcomes. The Cochrane database of systematic reviews. 2009(3):Cd000072. Epub 2009/07/10. PMID: 19588316. http://dx.doi.org/10.1002/14651858.CD000072.pub2

[21] Gosfield AG, Reinertsen JL. Finding Common Cause in Quality: Confronting the Physician Engagement Challenge. Physician Executive. 2008; 34(2): 26-31. PMid: 18441740.

[22] Snell AJ, Briscoe D, Dickson G. From the Inside Out: The Engagement of Physicians as Leaders in Health Care Settings. Qualitative Health Research. 2011; 21(7): 952-67. http://dx.doi.org/10.1177/1049732311399780

[23] Lindgren Å, Bååthe F, Dellve L. Why risk professional fulfilment: a grounded theory of physician engagement in healthcare development. The International Journal of Health Planning and Management. 2013; 28(2): e138-e57. http://dx.doi.org/10.1002/hpm.2142

[24] Baathe F, Norback LE. Engaging physicians in organisational improvement work. Journal of health organization and management. 2013; 27(4): 479-97. Epub 2013/09/06. PMID: 24003633.

[25] Patton MQ. Qualitative research \& evaluation methods. London: SAGE. 2002.

[26] Kvale S, Brinkmann S. Den kvalitativa forskningsintervjun. Lund: Studentlitteratur. 2009.

[27] Stacey RD. Strategic management and organisational dynamics: the challenge of complexity to ways of thinking about organisations. Harlow, England: Financial Times Prentice Hall. 6th edition. 2011.

[28] Czarniawska B. Narratives in social science research. London: SAGE. 2004.

[29] Miles MB, Huberman AM. Qualitative data analysis: an expanded sourcebook. Thousand Oaks, CA: Sage. 1994.

[30] The act of ethical trail of research concerning humans. Act 2003:460, amended 2008:192. Stockhom: Ministry of Education and Research. Available from: http://www.notisum.se (Accessed 2014-02-10)

[31] Donabedian A. The quality of care: How can it be assessed? JAMA. 1988; 260(12): 1743-8. http://dx.doi.org/10.1001/jama.1988.03410120089033

[32] Sweet GS, Wilson HJ. A patient's experience of ward rounds. Patient Education and Counseling. 2011; 84(2): 150-1. http://dx.doi.org/10.1016/j.pec.2010.08.016

[33] Lancet-editorial. Ward rounds: what goes around comes around. The Lancet. 2012; 380(9850): 1281. http://dx.doi.org/10.1016/S0140-6736(12)61740-1

[34] Malterud K. The art and science of clinical knowledge: evidence beyond measures and numbers. The Lancet. 2001; 358(9279): 397-400. http://dx.doi.org/10.1016/S0140-6736(01)05548-9

[35] Bharwani AM, Harris GC, Southwick FS. Perspective: A Business School View of Medical Interprofessional Rounds: Transforming Rounding Groups Into Rounding Teams. Academic Medicine. 2012; 87(12): 1768-71. http://dx.doi.org/10.097/ACM.0b013e318271f8da

[36] Levinson W, Lesser CS, Epstein RM. Developing Physician Communication Skills For Patient-Centered Care. Health Affairs. 2010; 29(7): 1310-8. http://dx.doi.org/10.1377/hlthaff.2009.0450

[37] Stickrath C, Noble M, Prochazka A, et al. Attending rounds in the current era: What is and is not happening. JAMA Internal Medicine. 2013; 173(12): 1084-9. http://dx.doi.org/10.1001/jamainternmed.2013.6041

[38] Herring R, Desai T, Caldwell G. Quality and safety at the point of care: how long should a ward round take? Clinical Medicine. 2011; 11(1): 20-2. http://dx.doi.org/10.7861/clinmedicine.11-1-20

[39] Ward DR, Ghali WA, Graham A, Lemaire JB. A real-time locating system observes physician time-motion patterns during walk-rounds: a pilot study. BMC medical education. 2014; 14: 37. Epub 2014/02/27. PMID: 24568589. http://dx.doi.org/10.1186/1472-6920-14-37

[40] Gawande A. BIG MED. New Yorker. 2012; 88(24): 52-63. PMID: 78418804.

[41] Chiara Margherita Santomauro CJK, Sidney Dekker Second victims, organizational resilience and the role of hospital administration. Journal of Hospital Administration. 2014; 3(5). http://dx.doi.org/10.5430/jha.v3n5p95

[42] Halpern SD, Detsky AS. Graded Autonomy in Medical Education - Managing Things That Go Bump in the Night. New England Journal of Medicine. 2014; 370(12): 1086-9. PMID: 24645941. http://dx.doi.org/10.1056/NEJMp1315408

[43] Arnetz BB. Psychosocial challenges facing physicians of today. Social Science \& Medicine. 2001; 52(2): 203-13. http://dx.doi.org/10.1016/S0277-9536(00)00220-3 
[44] Dall 'Alba G. Learning to be professionals. 1st ed. New York: Springer; 2009.

[45] Dall'Alba G. Understanding professional practice: investigations before and after an educational programme1. Studies in Higher Education. 2004; 29(6): 679-92. http://dx.doi.org/10.1080/0307507042000287195

[46] Birkmeyer JD, Finks JF, O'Reilly A, Oerline M, Carlin AM, Nunn AR, et al. Surgical Skill and Complication Rates after Bariatric Surgery. New England Journal of Medicine. 2013; 369(15): 1434-42. PMID: 24106936. http://dx.doi.org/10.1056/NEJMsa1300625

[47] Christensen J, Levinson W, Dunn P. The heart of darkness. J Gen Intern Med. 1992; 7(4): 424-31. http://dx.doi.org/10.1007/BF02599161

[48] Mørk BE, Hoholm T, Ellingsen G, Edwin B, Aanestad M. Challenging expertise: On power relations within and across communities of practice in medical innovation. Management Learning. 2010; 41(5): 575-92. http://dx.doi.org/10.1177/1350507610374552

[49] Reinertsen JL, Bisognano M, Pugh MD. Seven Leadership Leverage Points for Organization-Level Improvement in Health Care (Second Edition). IHI Innovation Series white paper. Cambridge, MA: Institute for Healthcare Improvement. 2008. (Available on www.IHI.org): http://www.ihi.org/resources/Pages/IHIWhitePapers/SevenLeadershipLeveragePointsWhitePaper.aspx

[50] Van Maanen J, Barley, Stephen R. Occupational communities: culture and control in organizations. Research in Organizational Behavior. 1984; 6: 287-365.

[51] Larsson S. A pluralist view of generalization in qualitative research. International Journal of Research \& Method in Education. 2009; 32(1): 25-38. http://dx.doi.org/10.1080/17437270902759931 